\title{
EVALUASI MANAJEMEN WAKTU PROYEK MENGGUNAKAN METODE PERT DAN CPM PADA PENGERJAAN "PROYEK REPARASI CRANE LAMPSON" DI PT MCDERMOTT INDONESIA
}

\author{
Junafuji Oka ${ }^{1)}$ Dwi Kartikasari ${ }^{2)}$ \\ 1) Prodi Administrasi Bisnis Terapan Politeknik Negeri Batam, email: junafujioka@gmail.com \\ 2)Prodi Administrasi Bisnis Terapan Politeknik Negeri Batam, email: dwi@ polibatam.ac.id
}

\begin{abstract}
Project scheduling is one of the elements of planning outcomes, which can provide information about project schedules and project progress in terms of resource performance in terms of cost, labor, equipment and materials and project duration plan with time efficiency for project completion. Critical Path Method (CPM) and Project Evaluation Review Technic (PERT) are two project scheduling methods that use different approaches in the process. In making a project, the researcher assumes that the initial success of a project should begin with the planning and preparation of the correct phase and the systematic stage.
\end{abstract}

Keywords: Scheduling, CPM, PERT.

\section{Abstrak}

Penjadwalan proyek merupakan salah satu elemen hasil perencanaan, yang dapat memberikan informasi tentang jadwal rencana dan kemajuan proyek dalam hal kinerja sumber daya berupa biaya, tenaga kerja, peralatan dan material serta rencana durasi proyek dengan pengefisiensian waktu untuk penyelesaian proyek. Critical Path Method (CPM) dan Project Evaluation Review Technic ( PERT ) merupakan dua metode penjadwalan proyek yang menggunakan pendekatan berbeda dalam pengerjaanya. Dalam membuat suatu proyek, peneliti menganggap bahwa awal keberhasilan suatu proyek harus dimulai dengan perencanaan dan penyusunan tahap yang benar serta tahap yang sistematis.

Kata Kunci: Penjadwalan, CPM,PERT 


\section{PENDAHULUAN}

Manajemen merupakan proses terpadu dimana individu-individu sebagai bagian dari organisasi dilibatkan untuk memelihara, mengembangkan, mengendalikan, dan menjalankan program-program yang semuanya diarahkan pada sasaran yang telah ditetapkan dan berlangsung terus menerus seiring dengan berjalannya waktu. Sedangkan proyek adalah upaya yang diorganisasikan untuk mencapai tujuan, sasaran dan harapan-harapan penting dengan menggunakan anggaran dana serta sumber daya yang tersedia, yang harus diselesaikan dalam jangka waktu tertentu.Secara historis, industri konstruksilah yang pertama menerapkan dan merupakan pengguna utama dari metode manajemen proyek. Biasanya metode ini di terapkan hanya untuk proyek-proyek fisik atau yang nyata (tangible project). Dewasa ini makin banyak pihak yang telah merasakan manfaat dari penerapan metode manajemen proyek untuk proyek-proyek yang non fisik atau intangible. Seperti industri Telekomunikasi, Perbankan, Teknologi Informasi, dll. Dalam pelaksanaannya proyek-proyek konstruksi pada umumnya banyak menghadapi permasalahan baik berkaitan dengan waktu, biaya maupun mutu. Penjadwalan proyek merupakan salah satu elemen hasil perencanaan, yang dapat memberikan informasi tentang jadwal rencana dan kemajuan proyek dalam hal kinerja sumber daya berupa biaya, tenaga kerja, peralatan dan material serta rencana durasi proyek dengan pengefisiensian waktu untuk penyelesaian proyek. Critical Path Method (CPM) dan Project Evaluation Review Technic ( PERT ) merupakan dua metode penjadwalan proyek yang menggunakan pendekatan berbeda dalam pengerjaanya. Dalam membuat suatu proyek, peneliti menganggap bahwa awal keberhasilan suatu proyek harus dimulai dengan perencanaan dan penyusunan tahap yang benar serta tahap yang sistematis. Proyek merupakan suatu aktivitas yang baru sehingga tingkat ketidakpastian dan risikonya juga sangat tinggi. Karena tingginya ketidakpastian tersebut, akan lebih sulit untuk memperkirakan tingkat sumber tenaga dan mempersulitperkiraan waktu yang dikehendaki untuk menyelesaikan suatu proyek.

Berdasarkan latar belakang yang diuraikan di atas, maka penulis tertarik untuk melakukan penelitian di PT McDermott
Indonesia dengan judul "Evaluasi Manajemen Waktu Proyek Menggunakan Metode PERT dan CPM Pada Pengerjaan "Proyek Reparasi Crane Lampson" di PT Mcdermott Indonesia".

\section{Rumusan Masalah}

Berdasarkan latar belakang yang telah dijelaskan di atas, maka dapat dirumuskan permasalahan sebagai berikut:

1. Apakah pihak perusahaan telah menggunakan metode PERT dan CPM dalam penjadwalan waktu dalam pengerjaan "Proyek Reparasi Crane Lampson".

2. Bagaimana cara menentukan lintasan kritis pada penjadwalan "Proyek Reparasi Crane Lampson" dengan menggunakan metode PERT dan CPM.

3. Berapa waktu yang dibutuhkan pada pengerjaan "Proyek Reparasi Crane Lampson" menggunakan metode PERT dan CPM.

4. Bagaimana evaluasi penjadwalan riil "Proyek Reparasi Crane Lampson" jika dibandingkan dengan penjadwalan dengan metode PERT dan CPM.

\section{Tujuan Penelitian}

Berdasarkan rumusan masalah tersebut, peneliti ingin menemukan bukti empiris mengenai hal-hal sebagai berikut:

1. Untuk mengetahui apakah pihak perusahaan telah menggunakan metode PERT dan CPM dalam penjadwalan waktu dalam pengerjaan "Proyek Reparasi Crane Lampson".

2. Untuk menentukan lintasan kritis pada penjadwalan "Proyek Reparasi Crane Lampson" dengan menggunakan metode PERT dan CPM.

3. Untuk mengetahui berapa waktu yang dibutuhkan pada pengerjaan "Proyek Reparasi Crane Lampson" menggunakan metode PERT dan CPM.

4. Untuk mengetahui evaluasi penjadwalan riil "Proyek Reparasi Crane Lampson" jika dibandingkan dengan penjadwalan dengan metode PERT dan CPM.

\section{METODE PENELITIAN \\ Desain atau Rancangan penelitian}

Penelitian yang digunakan adalah deskriptif kualitatif. Hal ini disebabkan tujuan dari penelitian ini akan menjawab pertanyaan mengenai deskripsi proyek riil dengan proyek yang menggunakan metode PERT dan CPM. 
Junafuji Oka \& Dwi, Evaluasi Manajemen Waktu Proyek...

\section{Objek dan Ruang Lingkup Penelitian}

Adapun yang menjadi objek penelitian ini adalah"Proyek Reparasi Crane Lampson"di Mechanical/Electrical Maintenance Department PT McDermott Indonesia. "Proyek Reparasi Crane Lampson" adalah proyek perbaikan alat berat yang sifatnya insidental. Pengerjaan proyek ini dilakukan disaat alat berat tersebut mengalami kerusakan dan proses perbaikan membutuhkan durasi pengerjaan yang cukup panjang, sehingga peneliti memilih proyek tersebut sebagai objek penelitian.

\section{Populasi dan Sampel}

Peneliti akan meneliti "Proyek Reparasi Crane Lampson" di PT. Mcdermott Indonesia yang dikerjakan dalam 2 tahun terakhir yaitu dari tahun 2016-2017. Teknik dalam pengambilan sampel ini menggunakan Teknik Purposive Sampling. Pengertian purposive sampling adalah teknik mengambil sampel dengan tidak berdasarkan random, daerah atau strata, melainkan berdasarkan atas adanya pertimbangan yang berfokus pada tujuan tertentu (Arikunto, 2006).

\section{Jenis dan Sumber Data}

Peneliti akan menggunakan strategi pengumpulan data opini dan arsip karena peneliti merasa metode ini sangat tepat digunakan dalam penelitian ini. Strategi pengumpulan data opini digunakan saat langsung menemui sumber data yaitu karyawan PT McDermott Indonesia dengan melakukan wawancara. Strategi pengumpulan data arsip dikumpulkan dari catatan pengerjaan proyek "Reparasi Crane Lampson" yang sudah ada. Jenis data yang digunakan adalah data primer dan data sekunder. Menurut Sarwono (2006), dilihat dari sumber perolehannya, data dapat dibagi menjadi dua jenis yaitu data primer dan data sekunder. Sumber data primer adalah data penelitian secara langsung dari sumber asli atau pertama. Sehingga data yang penulis peroleh dari metode wawancara merupakan data primer dalam penelitian ini Sedangkan data sekunder merupakan data penelitian yang diperoleh peneliti secara tidak langsung atau melalui media perantara. Sehingga data yang penulis peroleh dengan cara mengumpulkan arsip merupakan data sekunder dalam penelitian ini.

\section{Teknik Pengumpulan Data}

Peneliti akan menggunakan Teknik Observasi, Wawancara dan Dokumentasi. Teknik pengumpulan data merupakan caracara untuk memperoleh data dan keterangan yang diperlukan dalam penelitian. Untuk menunjang hasil penelitian, maka peneliti melakukan pengumpulan data yang diperlukan dengan cara Observasi, yaitu peneliti mendatangi dan mengamati obyek yang akan diteliti yaitu "Proyek Reparasi Crane Lampson" sehingga peneliti memperoleh beberapa informasi dan data yang dibutuhkan.Teknik pengumpulan data dengan wawancara, yaitu peneliti melakukan tanya jawab dengan daftar pertanyaan terlampir kepada pihak-pihak yang terkait yaitu 1 orang superintendent, 1 orang supervisor, 1 orang foreman dan 2 orang craftman yang mengerjakan proyek tersebut. Teknik pengumpulan data dokumentasi adalah informasi yang berasal dari catatan penting baik dari lembaga atau organisasi maupun dari perorangan. Dokumentasi penelitian ini merupakan pengambilan gambar oleh peneliti untuk memperkuat hasil penelitian.

\section{Metode Analisis Data}

Analisis data pada penelitian ini dilakukan dengan menggunakan metode PERT dan CPM, dengan berdasarkan data pengerjaan proyek riil. Data diolah berdasarkan data yang diperoleh dari hasil pengumpulan data. Dalam penelitian ini digunakan teknik analisis deskriptif kualititatif. Tahapan-tahapan yang dilakukan pada penelitian ini ialah:

1. Riset Operasi

Riset operasi diartikan sebagai peralatan manajemen yang menyatukan ilmu pengetahuan, matematika dan logika dalam rangka memecahkan masalahmasalah yang dihadapi sehari-hari sehingga akhirnya permasalahan tersebut dapat dipecahkan secara optimal (Subagyo, dkk, 2010). Sebagai alat suatu pemecahan masalah riset operasi harus dipandang sebagai ilmu dan seni, aspek ilmu terletak pada penggunaan teknikteknik dan algoritma-algoritma matematika untuk memecahkan persoalan yang dihadapi, sedangkan sebagai seni ialah karena keberhasilannya dari solusi matematis ini sangat bergantung pada kreativitas dan kemampuan seseorang sebagai penganalisa dalam pengambilan keputusan (Dimyati dan Dimyati, 2011).

2. Network

Tim riset operasi mengembangkan sistem pengambilan keputusan yang didasarkan pada optimasi dengan menggunakan metode jaringan kerja. 
Jaringan kerja (model network) adalah suatu diagram yang digunakan untuk membantu menyelesaikan masalah matematika yang cukup rumit agar menjadi lebih sederhana dan mudah diamati. Masalah-masalah yang dapat diatasi dengan network antara lain masalah penjadwalan (network planing), masalah transportasi, masalah penugasan, masalah penggantian peralatan, dan masalah lintasan terpendek. Network planning pada prinsipnya adalah hubungan ketergantungan antara bagianbagian pekerjaan atau variabel yang digambarkan atau divisualisasikan dalam diagram network. Dengan demikian dapat dikemukakan bagian-bagian pekerjaan yang harus didahulukan, bila perlu dilembur atau tambah biaya.

\section{Waktu dan Tempat Penelitian}

Penelitian ini di lakukan di PT McDermott Indonesia Jalan Bawal No.1, Batu Ampar, Kota Batam.

\section{HASIL PENELITIAN DAN PEMBAHASAN}

\section{A. Penjadwalan Proyek Riil}

1. Deskripsi Proyek

Proyek pengerjaan Crane Lampson adalah kegiatan perbaikan alat berat yang dipakai sebagai alat pengangkat dalam proyek kontruksi. Crane bekerja dengan mengangkat material yang akan dipindahkan lalu memindahkan dengan cara horizontal. Untuk menyusun durasi penjadwalan proyek, perusahaan menggunakan aplikasi khusus yang dimiliki dan dikerjakan oleh $E \& M$ engineer yang sifatnya rahasia/confidential. Proyek ini dikerjakan pada tanggal 29 April 2016 sampai 11 Agustus 2016 selama 105 Hari. Proyek ini memiliki target pengerjaan sampai akhir Agustus 2016 yaitu selama 125 hari dihitung sejak tanggal proyek dimulai.

2. Ruang Lingkup Proyek

Proyek perbaikan ini dikerjakan oleh karyawan Maintenance Department yaitu 8 orang craftman diawasi oleh 2 supervisor yang bekerja secara shift/pembagian waktu siang dan malam dengan masing-masing 4 orang craftman dan 1 supervisor siang dan malam. Kegiatan perbaikan tersebut dilakukan di fabrication yard.

3. Penjadwalan
Tabel di bawah ini adalah kegiatan perbaikan proyek tersebut.

4. Sumber Data

Berdasarkan data pengerjaan proyek yang telah diperoleh dari hasil wawancara. Diketahui bahwa durasi keseluruhan proyek dikerjakan selama 105 hari. Dimulai dengan dua kegiatan awal yaitu kegiatan A dengan durasi kerja 14 hari dan kegiatan B 21 hari. Setelah kegiatan A selesai kemudian dilanjutkan dengan kegiatan $\mathrm{C}$ dengan durasi kerja selama 14 hari. Setelah kegiatan C selanjutnya kegiatan dibagi menjadi 2 kegiatan yang menjadi kegiatan $\mathrm{F}$ dengan durasi kerja 21 hari dan kegiatan E dengan durasi 28 hari. Kembali ke kegiatan $\mathrm{B}$, selanjutnya ialah kegiatan D dengan durasi kerja 28 hari. Setelah kegiatan D dan E selesai, dua kegiatan tersebut mengarah ke satu kegiatan, yaitu kegiatan G. Perlu diketahui bahwa path AC-E memiliki total 56 hari kerja, dan path B-D memiliki total durasi kerja 49 hari. Maka diketahui bahwa untuk melanjutkan ke kegiatan $\mathrm{G}$, kegiatan $\mathrm{D}$ menunggu selama 7 hari sampai kegiatan E selesai. Setelah kegiatan D dan E selesai maka diteruskan ke kegiatan $\mathrm{G}$ dengan durasi kerja 35 hari. Dan sampai ke kegiatan akhir yaitu kegiatan $\mathrm{H}$. kegiatan $\mathrm{H}$ dapat dilaksanakan apabila kegiatan $\mathrm{F}$ dan $\mathrm{G}$ telah selesai. Diketahui bahwa path A-C-F memiliki total durasi 49 hari dan path A-CE-G memiliki total durasi 91 hari kerja. Maka untuk melajutkan ke kegiatan $\mathrm{H}$, kegiatan $\mathrm{F}$ menunggu selama 42 hari sampai kegiatan $\mathrm{G}$ selesai. Apabila total durasi pengerjaan masing-masing kegiatan dijumlahkan, didapatlah hasil pengerjaan selama 175 hari. Karena ada kegiatan yang dikerjakan secara bersamaan dan ada kegiatan yang dikerjakan harus menunggu kegiatan lain selesai terlebih dahulu. Maka didapatlah total durasi riil pengerjaan proyek tersebut selama 105 hari. Dalam penyusunan kegiatan ini perusahaan tidak menentukan jalur kritis yang dilalui, hal ini tidak dilakukan karena perusahaan memiliki teknik sendiri yang digunakan untuk menyusun kegiatan tersebut. Diketahui melalui hasil wawancara bahwa perusahaan menggunakan teknik expert judgement yaitu menggunakan penilaian dari ahli dan menggunakan teknik analogous estimating yaitu melakukan 
Junafuji Oka \& Dwi, Evaluasi Manajemen Waktu Proyek...

analogi dari kegiatan sebelumnya dan melakukan estimasi dengan menyesuaikan parameter yang dilakukan di kegiatan sebelumnya, seperti durasi, jam kerja yang digunakan untuk menentukan kegiatan pendahulu masing-masing kegiatan, dan jumlah karyawan. Berikut tabel rincian waktu penyelesaian setiap aktivitas dan urutan yang dilakukan berdasarkan penjelasan diatas.

\begin{tabular}{|l|l|}
\hline Penjelasan & $\begin{array}{l}\text { Durasi } \\
\text { Pengerjaan } \\
\text { (Hari) }\end{array}$ \\
\hline UHMW Bearing Set 11149 & 14 \\
\hline $\begin{array}{l}\text { King Pin Bushing And } \\
\text { Thrust Washer }\end{array}$ & 21 \\
\hline Swifel Bearing Housing & 14 \\
\hline Stinger Swifel Tube & 28 \\
\hline UHMW Bearing Set 11388 & 28 \\
\hline Drive Sprocket & 21 \\
\hline $\begin{array}{l}\text { Mast Bolt c/w Nut And } \\
\text { Washer }\end{array}$ & 35 \\
\hline $\begin{array}{l}\text { Boom Bolt c/w Nut And } \\
\text { Washer }\end{array}$ & 14 \\
\hline Total Durasi Pengerjaan & 175 \\
\hline
\end{tabular}

Berikut adalah tabel kegiatan pendahulu dalam pengerjaan proyek.

\begin{tabular}{|l|l|l|}
\hline Kegiatan & Keterangan & $\begin{array}{l}\text { Kegiatan } \\
\text { Pendahulu }\end{array}$ \\
\hline A & $\begin{array}{l}\text { UHMW Bearing Set } \\
11149\end{array}$ & - \\
\hline B & $\begin{array}{l}\text { King Pin Bushing And } \\
\text { Thrust Washer }\end{array}$ & - \\
\hline C & Swifel Bearing Housing & A \\
\hline D & Stinger Swifel Tube & B \\
\hline E & $\begin{array}{l}\text { UHMW Bearing Set } \\
11388\end{array}$ & C \\
\hline F & Drive Sprocket & C \\
\hline G & $\begin{array}{l}\text { Mast Bolt c/w Nut And } \\
\text { Washer }\end{array}$ & D, E \\
\hline H & $\begin{array}{l}\text { Boom Bolt c/w Nut And } \\
\text { Washer }\end{array}$ & F, G \\
\hline
\end{tabular}

Dari tabel diatas dapat digambarkan jaringan kerja Reparasi Crane Lampson seperti gambar dibawah ini.

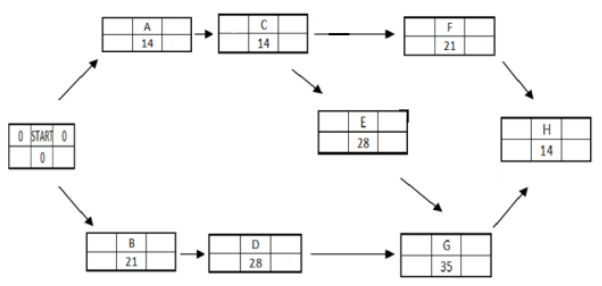

\section{B. Jalur Path}

Berdasarkan Jaringan kerja yang telah di buat sebelumnya maka didapatlah jalur masingmasing path, yaitu :

$$
\text { 1. Start }-B-D-G-H
$$

2. Start $-\mathrm{A}-\mathrm{C}-\mathrm{F}-\mathrm{H}$

3. Start $-\mathrm{A}-\mathrm{C}-\mathrm{E}-\mathrm{G}-\mathrm{H}$

dengan hasil hitungan untuk masing-masing path ialah :

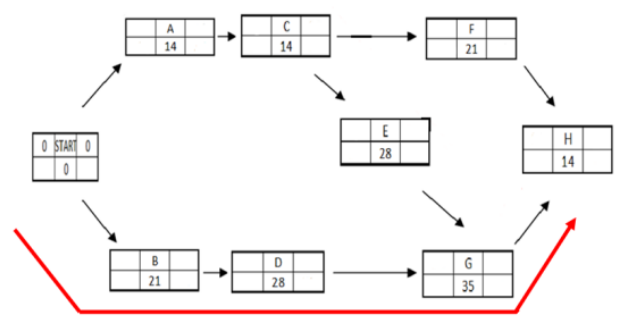

1. $\mathrm{B}-\mathrm{D}-\mathrm{G}-\mathrm{H}=21+28+35+14=98$ hari

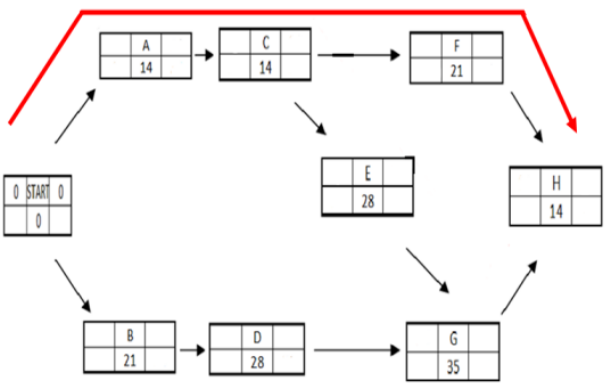

2. $\mathrm{A}-\mathrm{C}-\mathrm{F}-\mathrm{H}=14+14+21+14=63$ hari

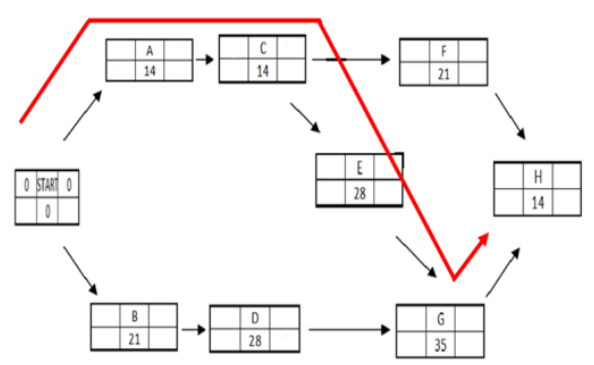

3. $\mathrm{A}-\mathrm{C}-\mathrm{E}-\mathrm{G}-\mathrm{H}=14+14+28+35+14=$ 105 hari

Maka diketahui pengerjaan terlama ialah melalui jalur $\mathrm{A}-\mathrm{C}-\mathrm{E}-\mathrm{G}-\mathrm{H}$ selama 105 hari dan pengerjaan tercepat ialah melalui jalur $\mathrm{A}-\mathrm{C}-\mathrm{F}-\mathrm{H}$ selama 63 hari.

C. Penentuan Waktu dan Narasumber

Untuk menentukan hasil to (optimistic time), tp (pessimistic time), dan tm (most likely time) dilakukan wawancara kepada 4 narasumber/responden yang di simbolkan R1 sebagai responden pertama, R2 sebagai responden kedua, R3 sebagai responden ketiga, dan R4 sebagai responden. Berikut tabel hasil wawancara. Responden dipilih karena responden sendiri yang melakukan kegiatan proyek tersebut. Untuk menentukan rata-rata $t a, t m, t b$ setiap kegiatannya maka dilakukan penghitungan.Menentukan rata-rata nilai ta. ta $=(\mathrm{R} 1+\mathrm{R} 2+\mathrm{R} 3+\mathrm{R} 4):$ 4. Untuk kegiatan $\mathrm{C}$ dengan hasil 12.75 maka dilakukan 
pembulatan menjadi 13. Menentukan rata-rata nilai $t m . t m=(\mathrm{R} 1+\mathrm{R} 2+\mathrm{R} 3+\mathrm{R} 4): 4$

\begin{tabular}{|l|c|l|}
\hline Kegiatan & $\boldsymbol{t} \boldsymbol{m}=(\mathbf{R} 1+\mathbf{R} \mathbf{2}+\mathbf{R} 3+\mathbf{R 4}): \mathbf{4}$ & Hasil \\
\hline A & $(21+21+21+21): 4$ & 14 \\
\hline B & $(21+21+21+21): 4$ & 21 \\
\hline C & $(14+14+14+14): 4$ & 14 \\
\hline D & $(28+28+28+28): 4$ & 28 \\
\hline E & $(28+28+28+28): 4$ & 28 \\
\hline F & $(21+21+21+21): 4$ & 21 \\
\hline G & $(35+35+35+35): 4$ & 35 \\
\hline H & $(14+14+14+14): 4$ & 14 \\
\hline
\end{tabular}

Menentukan rata-rata nilai $t b . t b=$ $(\mathrm{R} 1+\mathrm{R} 2+\mathrm{R} 3+\mathrm{R} 4): 4$

\begin{tabular}{|l|l|l|l|}
\hline $\begin{array}{l}\text { Kegiat } \\
\text { an }\end{array}$ & $\begin{array}{l}\boldsymbol{t} \boldsymbol{b}=(\mathbf{R} 1+\mathbf{R} 2+\mathbf{R} 3+\mathbf{R 4}) \\
: \mathbf{4}\end{array}$ & $\begin{array}{l}\text { Hasi } \\
\mathbf{l}\end{array}$ & $\begin{array}{l}\text { Hasil } \\
\text { Pembu } \\
\text { latan }\end{array}$ \\
\hline $\mathrm{A}$ & $(21+21+21+21): 4$ & 21 & 21 \\
\hline $\mathrm{B}$ & $(28+28+28+28): 4$ & 28 & 28 \\
\hline $\mathrm{C}$ & $(21+21+21+21): 4$ & 21 & 21 \\
\hline $\mathrm{D}$ & $(35+35+35+35): 4$ & 35 & 35 \\
\hline E & $(35+35+35+35): 4$ & 35 & 35 \\
\hline F & $(28+28+28+28): 4$ & 28 & 28 \\
\hline G & $(42+42+42+42): 4$ & 42 & 42 \\
\hline H & & 20.7 & 21 \\
\hline
\end{tabular}

\section{Langkah-langkah Metode PERT}

Garis besar Metode PERT ialah menggunakan tiga asumsi durasi aktivitas, yakni to (optimistic time), tp (pessimistic time), dan tm (most likely time) yang digunakan untuk menentukan te (Expected time). Dari hasil wawancara dengan beberapa sumber dilapangan didapatlah nilai waktu optimis (ta), waktu pesimis (tb) dan nilai $t m$.

\begin{tabular}{|l|l|l|l|}
\hline Kegiatan & $\boldsymbol{t a}$ & $\boldsymbol{t m}$ & $\boldsymbol{t} \boldsymbol{b}$ \\
\hline A & 12 & 14 & 21 \\
\hline B & 14 & 21 & 28 \\
\hline C & 13 & 14 & 21 \\
\hline D & 21 & 28 & 35 \\
\hline E & 21 & 28 & 35 \\
\hline F & 14 & 21 & 28 \\
\hline G & 28 & 35 & 42 \\
\hline H & 13 & 14 & 21 \\
\hline
\end{tabular}

Perhitungan menggunakan rumus :

$t e=(t a+4 t m+t b): 6$

maka didapatlah hasil perhitungan pada tabel

\begin{tabular}{|c|c|c|c|c|c|}
\hline Kegiatan & D & ES & \multicolumn{2}{|c|}{$\mathbf{E F}=\mathbf{D}+\mathbf{E S}$} & ah ini \\
\hline A & 14 & 0 & \multicolumn{2}{|c|}{14} & \\
\hline B & 21 & 0 & \multicolumn{2}{|c|}{21} & \\
\hline $\mathrm{C}$ & 14 & 14 & \multicolumn{2}{|c|}{28} & \\
\hline $\mathrm{D}$ & 28 & 21 & \multicolumn{2}{|c|}{49} & \\
\hline $\mathrm{E}$ & 28 & 28 & \multicolumn{2}{|c|}{56} & \\
\hline $\mathrm{F}$ & 21 & 28 & \multicolumn{2}{|c|}{49} & \\
\hline $\mathrm{G}$ & 35 & 56 & \multicolumn{2}{|c|}{91} & \\
\hline $\mathrm{H}$ & 14 & 91 & \multicolumn{2}{|c|}{105} & \\
\hline Kegiatan & \multicolumn{4}{|c|}{$\frac{1}{(t a+4 t m+t b): 6}$} & $t e$ \\
\hline $\mathrm{A}$ & \multicolumn{3}{|c|}{$(12+(4) 14+21): 6$} & \multicolumn{2}{|c|}{15} \\
\hline $\mathrm{B}$ & \multicolumn{3}{|c|}{ (14+(4)21+28): } & \multicolumn{2}{|c|}{21} \\
\hline $\mathrm{C}$ & \multirow{2}{*}{\multicolumn{3}{|c|}{$(13+(4) 14+21): 6$}} & \multicolumn{2}{|l|}{15} \\
\hline $\mathrm{D}$ & & & (21+(4)28+35): & \multicolumn{2}{|c|}{28} \\
\hline $\mathrm{E}$ & \multicolumn{4}{|c|}{$(21+(4) 28+35): 6$} & \\
\hline
\end{tabular}

\begin{tabular}{|c|c|c|}
\hline $\mathrm{F}$ & (14+(4)21+28):6 & 21 \\
\hline $\mathrm{G}$ & $(28+(4) 35+42): 6$ & 35 \\
\hline $\mathrm{H}$ & (13+(4)14+21): & 15 \\
\hline \multicolumn{3}{|c|}{$\begin{array}{l}\text { Setelah dilakukan perhitungan maka } \\
\text { didapatlah durasi baru pada penjadwalan } \\
\text { proyek tersebut menggunakan metode PERT. }\end{array}$} \\
\hline Kegiatan & Keterangan & $\begin{array}{l}\text { Durasi Pengerjaan } \\
\text { (Hari) }\end{array}$ \\
\hline A & $\begin{array}{l}\text { UHMW } \\
11149\end{array}$ Bearing Set & 15 \\
\hline B & $\begin{array}{l}\text { King Pin Bushing And } \\
\text { Thrust Washer }\end{array}$ & 21 \\
\hline $\mathrm{C}$ & $\begin{array}{ll}\text { Swifel } & \text { Bearing } \\
\text { Housing } & \end{array}$ & 15 \\
\hline $\mathrm{D}$ & Stinger Swifel Tube & 28 \\
\hline $\mathrm{E}$ & $\begin{array}{llr}\text { UHMW } & \text { Bearing } & \text { Set } \\
11388 & & \\
\end{array}$ & 28 \\
\hline $\mathrm{F}$ & Drive Sprocket & 21 \\
\hline G & $\begin{array}{l}\text { Mast Bolt c/w Nut And } \\
\text { Washer }\end{array}$ & 35 \\
\hline $\mathrm{H}$ & $\begin{array}{l}\text { Boom Bolt c/w Nut } \\
\text { And Washer }\end{array}$ & 15 \\
\hline Total Dura & engerjaan & 178 \\
\hline
\end{tabular}

\section{E. Langkah-langkah Metode CPM}

Kita menggunakan proses two-pass, terdiri atas forward pass dan backward pass untuk menentukan jadwal waktu untuk tiap kegiatan. ES (earlist start) dan EF (earlist finish) selama forward pass. LS (latest start) dan LF (latest finish) ditentukan selama backward pass.

\section{Hitungan Maju}

Dalam mengidentifikasi jalur kritis di pakai suatu cara yang disebut hitungan maju. Dan perlu di ingat kembali aturan dalam penyusunan jaringan kerja, terkecuali kegiatan awal, maka suatu kegiatan baru dapat di mulai bila kegiatan baru dapat dimulai bila kegiatan baru dapat dimulai bila kegiatan yang mendahuluinya telah selesai. Dengan rumus $\mathrm{EF}=\mathrm{ES}+\mathrm{D}$. Perhitungan maju untuk proyek riil digambarkan pada jaringan kerja berikut.

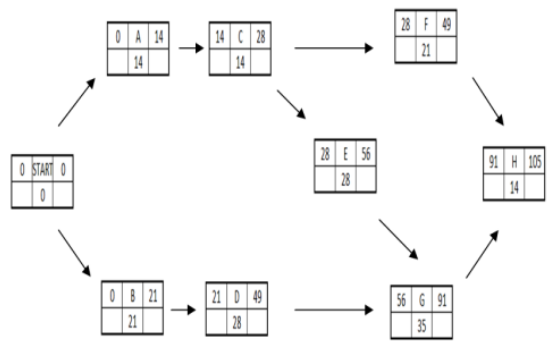

Hasil penghitungan maju kegiatan riil pada tabel dibawah ini.

Penghitungan maju yang didapat dari hasil penjadwalan dengan metode PERT digambarkan pada jaringan kerja berikut. 
Junafuji Oka \& Dwi, Evaluasi Manajemen Waktu Proyek...

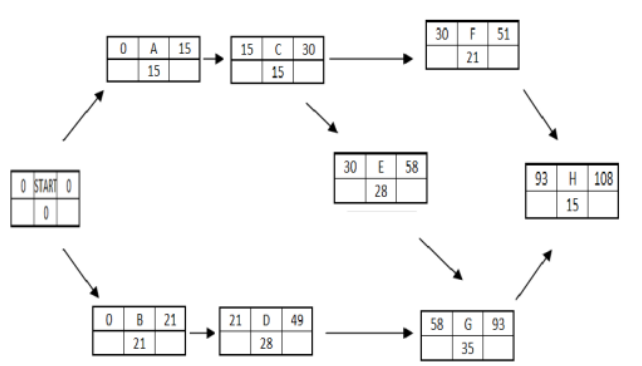

Hasil penghitungan maju kegiatan yang didapat dari hasil penjadwalan dengan metode PERT pada tabel dibawah ini.

\begin{tabular}{|l|l|l|l|}
\hline Kegiatan & D & ES & EF $=$ D + ES \\
\hline A & 15 & 0 & 15 \\
\hline B & 21 & 0 & 21 \\
\hline C & 15 & 15 & 30 \\
\hline D & 28 & 21 & 49 \\
\hline E & 28 & 30 & 58 \\
\hline F & 21 & 30 & 51 \\
\hline G & 35 & 58 & 93 \\
\hline H & 15 & 93 & 108 \\
\hline
\end{tabular}

\begin{tabular}{|l|l|l|l|l|l|l|}
\hline $\begin{array}{l}\text { Keg } \\
\text { iata } \\
\text { n }\end{array}$ & ES & EF & LS & LF & $\begin{array}{l}\text { Slack = } \\
\text { LS - ES }\end{array}$ & $\begin{array}{l}\text { Jalur } \\
\text { Kritis }\end{array}$ \\
\hline A & 0 & 14 & 0 & 14 & 0 & Ya \\
\hline B & 0 & 21 & 7 & 28 & 7 & Tidak \\
\hline C & 14 & 28 & 14 & 28 & 0 & Ya \\
\hline D & 21 & 49 & 28 & 56 & 7 & Tidak \\
\hline E & 28 & 56 & 28 & 56 & 0 & Ya \\
\hline F & 28 & 49 & 70 & 91 & 42 & Tidak \\
\hline G & 56 & 91 & 56 & 91 & 0 & Ya \\
\hline H & 91 & 105 & 91 & 105 & 0 & Ya \\
\hline
\end{tabular}

2. Hitungan Mundur

Untuk mendapatkan hitungan mundur dipakai aturan kerja yang menyatakan bahwa waktu mulai paling akhir suatu kegiatan adalah sama dengan waktu selesai paling akhir dikurangi kurun waktu berlangsungnya kegiatan bersangkutan atau LS=LF-D. Perhitungan mundur untuk proyek riil digambarkan pada jaringan kerja berikut.

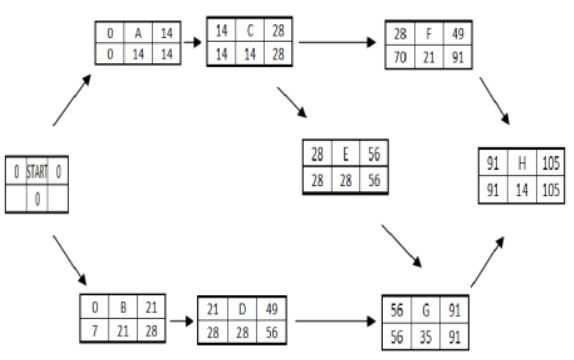

Hasil penghitungan mundur kegiatan riil pada tabel dibawah ini.

\begin{tabular}{|l|l|l|l|}
\hline Kegiatan & D & LF & LS = LF - D \\
\hline A & 14 & 14 & 0 \\
\hline B & 21 & 28 & 7 \\
\hline C & 14 & 28 & 14 \\
\hline D & 28 & 56 & 28 \\
\hline E & 28 & 56 & 28 \\
\hline
\end{tabular}

\begin{tabular}{|l|l|l|l|}
$\mathrm{F}$ & 21 & 91 & 70 \\
\hline $\mathrm{G}$ & 35 & 91 & 56 \\
\hline $\mathrm{H}$ & 14 & 105 & 91 \\
\hline
\end{tabular}

Penghitungan maju yang didapat dari hasil penjadwalan dengan metode PERT digambarkan pada jaringan kerja berikut.

Hasil penghitungan mundur kegiatan yang didapat dari hasil penjadwalan dengan metode PERT pada tabel dibawah ini.

\begin{tabular}{|l|l|l|l|}
\hline Kegiatan & D & LF & LS = LF - D \\
\hline A & 15 & 15 & 0 \\
\hline B & 21 & 30 & 9 \\
\hline C & 15 & 30 & 15 \\
\hline D & 28 & 58 & 30 \\
\hline E & 28 & 58 & 30 \\
\hline F & 21 & 93 & 72 \\
\hline G & 35 & 93 & 58 \\
\hline H & 15 & 108 & 93 \\
\hline
\end{tabular}

3. Hambatan aktivitas dan jalur krirtis

Waktu slack (slack time) yaitu waktu bebas yang dimiliki oleh setiap kegiatan untuk bias diundur tanpa menyebabkan keterlambatan proyek keseluruhan. Secara matematis waktu slack dapat dirumuskan : Slack $=\mathrm{LS}-$ ES. Berikut tabel waktu slack dan jalur kritis kegiatan riil.

Maka didapatlah jalur kritis pada project riil yaitu : A-C-E-G-H

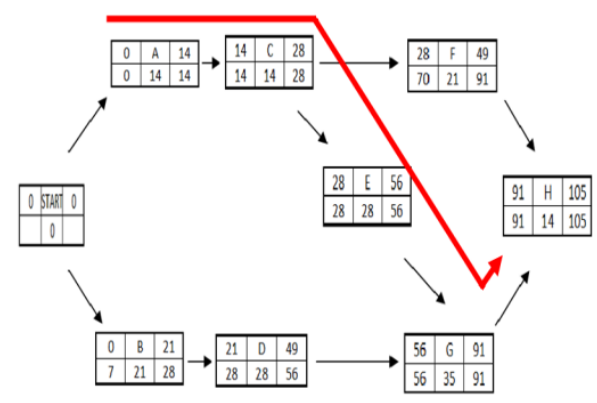

Berikut tabel waktu slack dan jalur kritis menggunakan metode PERT.

\begin{tabular}{|l|l|l|l|l|l|l|}
\hline Kegiatan & ES & EF & LS & LF & $\begin{array}{l}\text { Slack } \\
=\text { LS } \\
\text { ES }\end{array}$ & $\begin{array}{l}\text { Jalur } \\
\text { Kritis }\end{array}$ \\
\hline A & 0 & 15 & 0 & 15 & 0 & Ya \\
\hline B & 0 & 21 & 9 & 30 & 9 & Tidak \\
\hline C & 15 & 29 & 15 & 30 & 0 & Ya \\
\hline D & 21 & 49 & 30 & 58 & 9 & Tidak \\
\hline E & 30 & 58 & 30 & 58 & 0 & Ya \\
\hline F & 30 & 51 & 72 & 93 & 42 & Tidak \\
\hline G & 58 & 93 & 58 & 93 & 0 & Ya \\
\hline H & 93 & 108 & 93 & 108 & 0 & Ya \\
\hline
\end{tabular}

Maka didapatlah jalur kritis menggunakan metode PERT yaitu : A-C-E-G-H 

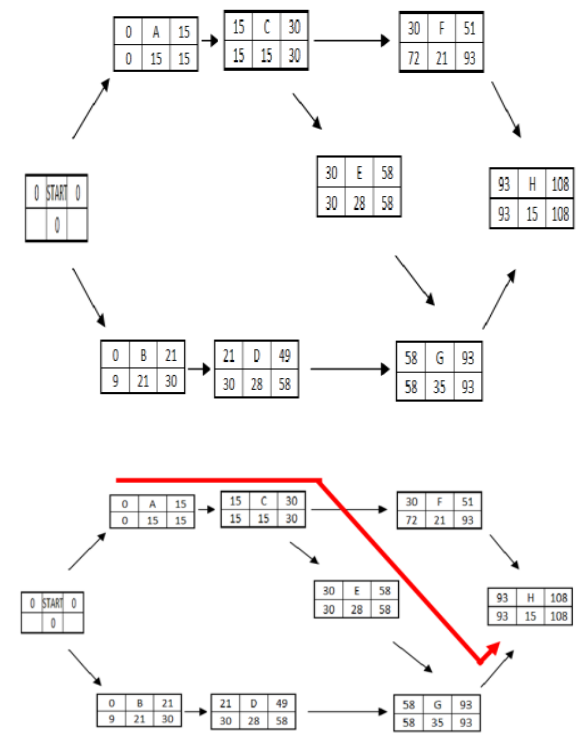

\section{KESIMPULAN DAN SARAN}

Berdasarkan hasil penelitian yang telah dilakukan mengenai "Evaluasi Manajemen Waktu Proyek Menggunakan Metode PERT dan CPM Pada Pengerjaan "Proyek Reparasi Crane Lampson" di PT Mcdermott Indonesia" maka didapatlah tujuan penelitian sebagai berikut.

1. Telah diketahui bahwa perusahaan tidak menggunakan metode PERT/CPM, melainkan menggunakan sebuah aplikasi khusus yang digunakan untuk melakukan penjadwalan kegiatan. Dan menggunakan teknik expert judgement yaitu menggunakan penilaian dari ahli. Dan menggunakan teknik analogous estimating yaitu melakukan analogi dari kegiatan sebelumnya yang digunakan untuk menentukan urutan kegiatan.

2. Cara menentukan lintasan kritis pada penjadwalan dilakukan dengan mengumpulkan data sekunder kemudian dilakukan wawancara untuk mendapatkan data primer. Kemudian peneliti merangkai path dan melakukan penghitungan untuk menentukan jalur kritis. Melalui hasil penghitungan menentukan jalur kritis menggunakan metode PERT/CPM maka didapatlah jalur kritis pada proyek riil yaitu melalui jalur $\mathrm{A}-\mathrm{C}-\mathrm{E}-\mathrm{G}-\mathrm{H}$.

3. Melalui hasil penghitungan menggunakan metode PERT/CPM maka didapatlah durasi pengerjaan proyek baru, yaitu selama 108 hari.
4. Berdasarkan data hasil penghitungan menggunakan metode PERT/CPM maka ditemukan selisih durasi pengerjaan proyek riil dengan durasi pengerjaan proyek baru bahwa penggunaan metode PERT/CPM memberikan durasi 3 hari lebih lama dari durasi kegiatan riil.

\section{Saran}

Berikut saran yang dapat diberikan peneliti.

1. Berdasarkan hasil kesimpulan diatas bukan berarti Metode PERT dan CPM memberikan durasi pengerjaan proyek lebih lama.

2. Penelitian selanjutnya diharapkan dapat menggunakan metode lain yang dapat dibandingkan dengan metode PERT dan CPM untuk melakukan penjadwalan Proyek.

\section{DAFTAR PUSTAKA}

Agyei, W.(2015). Project Planning And Scheduling Using PERT And CPM Techniques With Linear Programming: Case Study.International Journal of Scientific \& Technology Research, Volume 4, Issue 08.

Arikunto, S.(2006). Prosedur Penelitian: Suatu Pendekatan Praktek, Edisi Revisi. Jakarta : Rineka Cipta.

Badri, S.(2002). Dasar-dasar Network planning.Jakarta : Rineka Cipta.

Dimyati, T., dan Dimyati, A. (2011). Operation Research Model-model Pengambilan Keputusan. Bandung: Sinar Baru Algesindo.

Erikson, W,J,. and Hall, O. (1986). ModelModel Komputer Bagi Bisnis Anda.

Jakarta : PT Pustaka Binaman Pressindo.

Hayun, A.A.(2005). Perencanaan Dan Pengendalian Proyek Dengan Metode Pert-Cpm: Studi Kasus Fly Over Ahmad Yani Karawang.Journal The WINNERS, Vol. 1706 No. 2, September 2005: 155-174.

Jonathan, S. (2006). Metode Penelitian Kuantitatif dan Kualitatif, Yogyakarta : Graha Ilmu 
Junafuji Oka \& Dwi, Evaluasi Manajemen Waktu Proyek...

Kerzner, H. (2003). Project Management : A System Approach to Planning, Schedulling, and Controlling ( $8^{\text {th }}$ ed). New Jersey : John Wiley \& Son Inc.

Mendritfa, F. (2014). SEJARAH PT.McDERMOTT

INDONESIA (PTMI). Retrivied from https:// blognyafadli. wordpress.com/2014/02/12/sejarah-ptmcdermott-indonesia-ptmi/

Nugroho, A.A., (2007). Optimalisasi Penjadwalan Proyek pada Pembangunan Gedung Khusus (Laboratorium) Stasiun Karantina Ikan Kelas 1 Tanjung Mas, Semarang. Skripsi. Fakultas Matematika dan Ilmu Pengetahuan Alam Universitas Negeri Semarang.

Project Management Institute. (2008). A Guide To The Project ManagementBody of Knowledge $\left(4^{\text {th }}\right.$ ed).
Sentosa, B. (2009). Manajemen Proyek : Konsep dan Implementasi. Yogyakarta : Graha Ilmu.

Stelth, P., \& Roy, G, L,.(2009). Projects Analysis through CPM (Critical Path Method). School of Doctoral Studies (European Union), Journal - July, 2009 No. 1.

Subagyo, P., Asri, M., Handoko, T.,H. (2010). Dasar-dasar Operation Research. Yogyakarta : Edisi kedua BPFE.

Sugiyono. (2012) Memahami Penelitian Kualitatif. Bandung : ALFABETA

Taurusyanti, D., \& Lesmana, M.F. (2015). Optimalisasi Penjadwalan Proyek Jembatan Girder Guna Mencapai Efektifitas Penyelesaian dengan Metode Pert dan Cpm pada PT Buana Masa Metalindo. JIMFE (Jurnal Ilmiah Manajemen Fakultas Ekonomi), Volume 1 No. $1, \quad 32-36$ 